\title{
Reply to Discussion of "Observation of the Mold Filling Process of a Large Hydro-Turbine Guide Vane Casting"
}

\section{JINWU KANG, HAIMIN LONG, YONGJIE LI, RUI YOU, XIAOKUN HAO, GANG NIE, TIANJIAO WANG, and CHENGCHUN ZHANG}

DOI: $10.1007 / \mathrm{s} 11663-015-0389-8$

(C) The Minerals, Metals \& Materials Society and ASM International 2015

We appreciated Professor John Campbell's comments very much. The mold filling of liquid metals is very important, especially as the first step of making a casting. Therefore, the filling system design is a very serious work. The melt filling process has been a 1000 year mystery because it cannot be directly observed because of the mold obstacle. So, researchers have resorted to water analogy system. However, the analog results have been always doubted. In recent years, the X-ray observation method unveiled the filling process for specimens or small castings in laboratories. But, still some problems need to be solved such as dealing with the complicated and large castings. In our paper, we highlighted the effective direct observation system of mold filling and its successful application in a $10 \mathrm{t}$ heavy steel casting, i.e., the using of high temperatureresisted camera to directly observe the filling process of heavy steel castings weighing in tons, which is affordable and the liquid steel flow can be directly watched at real time. It is a very valuable method for foundries, especially for the production of heavy castings, the direct observation means optimization of filling system and finally reducing waste and improving casting quality. Up to now, this method have been used in seven new heavy castings in the foundry of Harbin Electric Machinery Co., Ltd., and some observation results approve the experience, while some are in contradiction with the experience.

As to the gating system design related to my paper, I agree with Professor John Campbell about the avoidance of the free fall of the melt in air or in the sprue to prevent inclusions and turbulence. However, in foundries, the filling system design is by theories with the consideration of the factors such as experience, cost, pouring ladle, and easy-going with on-site workers. Years ago I watched a bottom nozzle of a ladle was hardly opened till the end of filling of a heavy steel casting. Thus, in foundries, all these factors have to be considered, especially, in the production of heavy steel castings. Counter-gravity filling by using pressurized furnaces or pumps has been successfully applied in the production of aluminum castings; however, it is still hard to be adopted in steel castings up to date. The viewpoint about steady fluid flow in mold filling is easy to understand, but its importance in foundrymen minds varies. I will surely recommend these filling system design ideas and principles to foundries and assure them of their significance and effectiveness.
JINWU KANG, Associate Professor, HAIMIN LONG, RUI YOU, XIAOKUN HAO, GANG NIE, TIANJIAO WANG, Master Graduates, are with the School of Materials Science and Engineering, Key Laboratory for Advanced Materials Processing Technology, Tsinghua University, Beijing 100084, P.R. China. Contact e-mail: kangjw@tsinghua.edu.cn YONGJIE LI, Master Graduate, is with the Department of Mechanical Engineering, Tsinghua University, Beijing 100084, P.R. China. CHENGCHUN ZHANG, Senior Engineer, is with the Harbin Electric Machinery Co., LTD, Harbin 150040, P.R. China.

Manuscript submitted April 28, 2015.

Article published online June 17, 2015. 